\title{
Hepatocellular Carcinoma: Diagnosis and Therapeutic Options
}

\author{
Khairy Hammam Morsy ${ }^{1}$, Mahmoud Saif-Al-Islam ${ }^{1}$, Esraa Maher Ibrahim ${ }^{2}$ \\ ${ }^{1}$ Tropical Medicine and Gastroenterology Department, Faculty of Medicine, Sohag \\ University. ${ }^{2}$ Sohag Cancer Center, Sohag, Egypt.
}

\begin{abstract}
\section{Background}

HCC has become the third most common malignancy worldwide with very poor prognosis, rendering it the fourth highest cause of cancer related deaths $^{1,2}$. The distribution of liver cancer varies by region and more than $80 \%$ of cases and deaths occur in developing countries ${ }^{3}$. In Africa, liver cancer has been ranked as the fourth common cancer, and most of liver cancers are $\mathrm{HCC}^{4}$.
\end{abstract}

Hepatocellular carcinoma (HCC) is the most common primary neoplasm of the liver and a significant cause of mortality in patients with cirrhosis. Aim of this review is to summarize the new methods of diagnosis and therapeutic options.

\section{Epidemiology}

HCC represents $85 \%-90 \%$ of primary liver cancers accounting for $3.5 \%$ and $7.5 \%$ of all cancers among women and men respectively, and accounts for half a million deaths per year. In Middle Eastern countries, liver cancer is a major concern among men, especially in certain countries such as Egypt and Saudi Arabia, and to a lesser extent in other countries of this region. Recent reports demonstrate that the incidence of HCC has increased sharply in the last 5-10 years, with an especially high incidence in Egypt ${ }^{5}$.

\section{Risk factors}

The major risk factor for the development of HCC is cirrhosis of the liver. However, about one quarter of HCC cases diagnosed in the United States do not have any known predisposing risk factors. The major known risk factors for $\mathrm{HCC}$ are viral (chronic hepatitis B and hepatitis C), toxic (alcohol and aflatoxins), metabolic (diabetes and non-alcoholic fatty liver disease, hereditary haemochromatosis) and immunerelated (primary biliary cirrhosis and autoimmune hepatitis) ${ }^{6}$. Recently, the geographical variability in the incidence of HCC has been attributed to the changing distribution and the natural history of Hepatitis B virus (HBV) and Hepatitis C virus (HCV) infection? ${ }^{7}$.

\section{Diagnosis of HCC}

\section{- Clinical presentation}

In most HCC cases, clinical signs and symptoms may occur several months after development, when therapy cannot be curative. Clinical signs and symptoms of hepatic cirrhosis that is often present in patients with HCC usually mask the presence of an underlying early hepatocellular carcinoma. Symptoms and signs of cirrhosis are often the only expression of the disease. Because of this, patients affected by HCC usually present at an advanced stage of the disease with clinical signs as jaundice, ascites, peripheral edemas, neurologic manifestations of hepatic encephalopathy, and bleeding ${ }^{8}$.

\section{- Laboratory diagnosis}

Since the early diagnosis of primary liver cancer (PLC) is particularly critical for the treatment efficacy and long-term survival, early screening and early surveillance should be emphasized. The routine screening includes alpha-fetoprotein (AFP) every 
six months for men $\geq 40$ years and women $\geq 50$ years who belong to the high-risk populations that have a history of $\mathrm{HBV} / \mathrm{HCV}$ infection, alcoholism, and/or diabetes and a family history of liver cancer. It is generally believed that AFP is a relatively specific tumor marker for $\mathrm{HCC}$; the continued AFP increase usually is a risk factor for $\mathrm{HCC}^{9}$.

Other tests include:

1. Des-gamma carboxyprothrombin (DCP)

DCP is an abnormal prothrombin protein that is found in the serum of patients with $\mathrm{HCC}$ and in patients with vitamin K-deficiency or on warfarin therapy ${ }^{10}$.

\section{Glypican-3 (GPC3)}

It is an oncofetal protein expressed in fetal liver and HCC. A clinical trial using a GPC3 peptide vaccine in patients with advanced HCC has been carried out, denoting that it serves not only as a tumor marker but also as a therapeutic target ${ }^{11}$.

2. Squamous cell carcinoma antigen (SCCA)

ISCCA is physiologically expressed in the skin and other squamous epithelial cells $^{12}$. It has been reported to be overexpressed in HCC tissue and in serum from patients with $\mathrm{HCC}^{13}$.

\section{Golgi protein 73 (GP73, also} known as Golph2)

It is a protein expressed by biliary epithelial cells in normal liver. It is upregulated in patients with acute hepatitis, cirrhosis and $\mathrm{HCC}^{14}$.

4. Hepatocyte growth factor (HGF)

HGF has been used as a prognostic marker in HCC. Serum HGF levels greater than or equal to $1.0 \mathrm{ng} / \mathrm{mL}$ have been associated with poor survival in HCC patients ${ }^{15}$.

\section{- Imaging diagnosis}

Imaging studies for diagnosis of HCC can fall into one of two main categories: routine non-invasive studies such as US, CT, and MRI, and more specialized invasive techniques including CT during hepatic arteriography, iodised oil-CT, and CT arterial portography in addition to the conventional hepatic angiography ${ }^{16}$.

1. Abdominal ultrasonography (US)

Abdominal US allows the recognition of tumours as small as $1 \mathrm{~cm}$ in size $\mathrm{e}^{16}$. US offers many signs that raise the suspicion of malignant transformation, including the presence of intrahepatic venous thrombosis, a mass protruding from the hepatic surface or dilated intrahepatic bile duct, even in the absence of a definite liver mass ${ }^{17}$.

\section{Multislice-helical (spiral) CT}

Abdominal multiphase perfusion CT is the technique of choice for diagnosis of HCC with an excellent performance in the early detection and staging of hepatic focal lesions ${ }^{17}$. The gold standard imaging modality for evaluating the response after locoregional intervention of HCC is Spiral $\mathrm{CT}^{18}$.

3. Magnetic resonance imaging (MRI)

The advantage of MRI over CT is obtaining images of the liver of highresolution without using ionizing radiation or nephrotoxic contrast agents. MRI has an equivalent diagnostic accuracy as helical CT in the early detection and diagnosis of $\mathrm{HCC}^{19}$.

\section{Therapeutic options}

HCC therapies are categorized as curative and palliative, which depend upon the tumor features, hepatic reserve, and presence or not of extrahepatic metastasis or vascular invasion. Manifold current treatment choices include: Surgical resection, liver transplantation, radiofrequency ablation (RFA), microwave ablation, percutaneous ethanol injection (PEI) or acetic acid ablation, transcatheter arterial chemoembolization (TACE), radioembolization, cryoablation, radiation therapy (RT), stereotactic radiotherapy, systemic chemotherapy, molecularly targeted therapies like sorafenib $^{20}$, and viscum fraxini ${ }^{21}$ 


\section{Summary and conclusion}

HCC is one of the commonest cancers worldwide. It is a major health problem and its incidence is increasing. More than 600,000 people die from it each year. The presence of cirrhosis is the major risk factor and this is largely due to chronic $\mathrm{HCV}$ and HBV infection.

Worldwide research on the disease needs to be intensified in both the medical and pharmaceutical fields, especially with a focus on providing help to areas where resources are limited.

\section{References}

1. Parkin DM, Bray F, Ferlay J, Pisani P (2005): Global cancer statistics, 2002. CA Cancer J Clin; 55: 74-108.

2. Parkin DM (2006): The global health burden of infectionassociated cancers in the year 2002. Int J Cancer; 118: 3030-44.

3. Hall AJ, Wild CP (2003): Liver cancer in low and middle income countries. BM.; 326: 994-5.

4. Parkin DM, Sitas F, Chirenje M, Stein L, Abratt R, Wabinga $\mathrm{H}$ (2008): Part I: cancer in indigenous Africans-burden, distribution, and trends. Lancet Oncol; 9: 683-92.

5. Poustchi H, Sepanlou S, Esmaili $\mathrm{S}$, Mehrabi N, Ansarymoghadam A (2010): Hepatocellular carcinoma in the world and the middle East. Middle East J Dig Dis; 2(1): 31-41.

6. Parikh S, Hyman D (2007): Hepatocellular cancer: a guide for the internist. Am J Med; 120: 194202.

7. Liu CJ, Kao JH (2007): Hepatitis B virus-related hepatocellular carcinoma: epidemiology and pathogenic role of viral factors. J Chin Med Assoc; 70: 141-5.

8. Trevisani F, D'Intino PE, Caraceni P, Pizzo M, Stefanini GF, Mazziotti A, Grazi GL, Gozzetti G, Gasbarrini G, Bernardi M (1995): Etiologic factors and clinical presentation of hepatocellular carcinoma. Differences between cirrhotic and non-cirrhotic Italian patients. Cancer; 75(9): 2220-32.

9. Qin S (2012): Primary Liver Cancer Diagnosis and Treatment Expert Panel of the Chinese Ministry of Health. Guidelines on the diagnosis and treatment of primary liver cancer (2011 edition). Chin Clin Oncol; 1: 10.

10. Wright LM, Kreikemeier JT, Fimmel CJ (2007): A concise review of serum markers for hepatocellular cancer. Cancer Detect Prev; 31: 35-44.

11. Sawada Y, Yoshikawa $T$, Nobuoka D, Shirakawa H, Kuronuma T, Motomura Y, Mizuno S, Ishii H, Nakachi K, Konishi M, Nakagohri T, Takahashi S, Gotohda N, Takayama T, Yamao K, Uesaka K, Furuse J, Kinoshita T, Nakatsura T (2012): Phase I trial of a glypican3- derived peptide vaccine for advanced hepatocellular carcinoma: immunologic evidence and potential for improving overall survival. Clin Cancer Res; 18: 3686-96.

12. Giannelli G, Fransvea E, Trerotoli $\mathrm{P}$, Beaugrand $\mathrm{M}$, Marinosci $\mathrm{F}$, Lupo L, Nkontchou G, Dentico P, Antonaci S (2007): Clinical validation of combined serological biomarkers for improved hepatocellular carcinoma diagnosis in 961 patients. Clin Chim Acta; 383: 147-52. 
13. Giannelli G, Marinosci F, Trerotoli P, Volpe A, Quaranta M, Dentico P, Antonaci S (2005): SCCA antigen combined with alphafetoprotein as serologic markers of HCC. Int $\mathrm{J}$ Cancer; 117: 506-9.

14. Kladney RD, Cui $X$, Bulla GA, Brunt EM, Fimmel CJ (2002): Expression of GP73, a resident Golgi membrane protein, in viral and nonviral liver disease. Hepatology; 35: 1431-40.

15. Chau GY, Lui WY, Chi CW, Chau YP, Li AF, Kao HL, Wu CW (2008): Significance of serum hepatocyte growth factor levels in patients with hepatocellular carcinoma undergoing hepatic resection. Eur J Surg Oncol; 34: 333-8.

16. Gomaa AI, Khan SA, Leen EL, Waked I, Taylor-Robinson SD (2009): Diagnosis of hepatocellular carcinoma. World $\mathbf{J}$ Gastroenterol; 15: 1301-14.

17. Yu SC, Yeung DT, So NM (2004): Imaging features of hepatocellular carcinoma. Clin Radiol; 59: 145-56.

18. Bruix J, Sherman M (2011): Management of hepatocellular carcinoma: an update. Hepatology; 53: 1020-2.

19. Yu NC, Chaudhari V, Raman SS, Lassman C, Tong MJ, Busuttil RW, Lu DS (2011): CT and MRI improve detection of hepatocellular carcinoma, compared with ultrasound alone, in patients with cirrhosis. Clin Gastroenterol Hepatol; 9: 161-7.

20. Attwa MH, El-Etreby SA (2015): Guide for diagnosis and treatment of hepatocellular carcinoma. World J Hepatol; 7(12): 1632-51.

21. Kienle GS, Kiene H (2010): Influence of Viscum album L (European Mistletoe) extracts on quality of life in cancer patients: a systematic review of controlled clinical studies. Integr Cancer Therap; 9(2):142-57. 